\title{
Epigenetic regulation in male germ cells
}

\author{
Natasha M Zamudio ${ }^{1,2}$, Suyinn Chong $^{3}$ and Moira K O'Bryan ${ }^{1,2}$ \\ ${ }^{1}$ Monash Institute of Medical Research, Monash University, Melbourne, Victoria 3168, Australia, ${ }^{2}$ Australian Research \\ Centre of Excellence in Biotechnology and Development, Monash University, Melbourne, Victoria 3168, Australia \\ and ${ }^{3}$ Queensland Institute of Medical Research, Brisbane, Queensland 4072, Australia
}

Correspondence should be addressed to M K O’Bryan; Email: moira.obryan@med.monash.edu.au

\begin{abstract}
In recent years, it has become increasingly clear that epigenetic regulation of gene expression is critical during spermatogenesis. In this review, the epigenetic regulation and the consequences of its aberrant regulation during mitosis, meiosis and spermiogenesis are described. The current knowledge on epigenetic modifications that occur during male meiosis is discussed, with special attention on events that define meiotic sex chromosome inactivation. Finally, the recent studies focused on transgenerational and paternal effects in mice and humans are discussed. In many cases, these epigenetic effects resulted in impaired fertility and potentially long-ranging affects underlining the importance of research in this area.

Reproduction (2008) 136 131-146
\end{abstract}

\section{Introduction}

Male infertility is a very common problem affecting 1 in 20 men in western populations. Although there is a large amount of research in the field, the underlying causes in many cases are unknown. Many studies have explored the genetic causes of human male infertility using mouse models (O'Bryan \& de Kretser 2006) or through candidate gene sequencing approaches using genomic DNA from infertile men (Miyamoto et al. 2003). As with other conditions including cancer, neurological and immune disorders, and even ageing (Egger et al. 2004, Rodenhiser \& Mann 2006), it is also likely that epigenetic changes will contribute to cases of male infertility.

Spermatogenesis is a highly regulated process; it is not surprising that epigenetic mechanisms are involved and that perturbations in these mechanisms can result in male infertility. There have been various links drawn between epigenetic mechanisms and important events during spermatogenesis, including chromosome condensation, $\mathrm{XY}$ body formation, retrotransposon silencing and packaging of DNA into the spermatid nucleus; however, the underlying molecular mechanisms are only now becoming clear. While epigenetic regulation is crucial in many systems within the body, this review will concentrate on spermatogenesis, male fertility and the consequences of aberrant regulation for offspring.

\section{Epigenetic modifications}

Epigenetics is the study of mitotically and/or meiotically heritable changes in gene expression or cellular phenotype, which occur without changes to the underlying DNA sequence (Goldberg et al. 2007). Epigenetic changes such as DNA methylation, histone methylation, histone acetylation and histone phosphorylation, and chromatin remodelling such as altering the position of nucleosomes all have a direct effect on chromatin structure. The ability to regulate chromatin structure is essential in eukaryotic organisms in order to organise the enormous sequence content of DNA into a compact arrangement and for defining which pieces of DNA are available for transcription. Indeed, chromatin structure is integral in defining both the phenotype of a cell and an organism as a whole.

Chromatin is made-up of histones and DNA, both of which may be modified to affect the way in which they interact. Histones are composed of predominantly positively charged amino acids, which allow them to bind with a high affinity to negatively charged DNA (Alberts et al. 1989). There are four types of nucleosomal histones: $\mathrm{H} 2 \mathrm{~A}, \mathrm{H} 2 \mathrm{~B}, \mathrm{H} 3$ and $\mathrm{H} 4$. Histones are responsible for the coiling of DNA into nucleosomes. Histone variants exist for histones $\mathrm{H} 3$ (CENP-A, H3.3), $\mathrm{H} 2 \mathrm{~A}(\mathrm{H} 2 \mathrm{AZ}, \mathrm{H} 2 \mathrm{AX}$, macroH2A) and $\mathrm{H} 2 \mathrm{~B}(\mathrm{TH} 2 \mathrm{~B})$. Each has a different role in maintaining chromatin structure. Two copies of each nucleosomal histone $(\mathrm{H} 2 \mathrm{~A}, \mathrm{H} 2 \mathrm{~B}, \mathrm{H} 3$ and $\mathrm{H} 4$ ) form a histone octamer core around which $147 \mathrm{bp}$ of double-stranded DNA is wound creating a nucleosome (reviewed in Zhang \& Reinberg 2001; Fig. 1). Nucleosomes are the basic subunit of chromatin. Linker DNA as well as histone $\mathrm{H} 1$ links all the nucleosomes together to create a $30 \mathrm{~nm}$ chromatin 

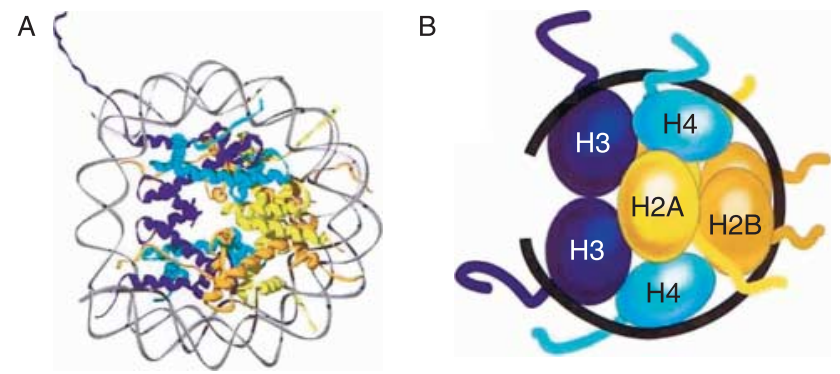

Figure 1 Nucleosome structure. (A) A model of a nucleosome representing the histone octamer core around which 147 bp of DNA is wrapped. (B) Schematic of a nucleosome. Black line represents DNA wrapped around octamer core. Amino-terminal tails extend out from the globular domain of each core histone (Allis et al. 2007).

fibre. Epigenetic mechanisms regulate the association between the DNA and histones in such a way that genes are made transcriptionally active or inactive.

Heterochromatin is chromatin that is transcriptionally inactive; that is, the genes within it are repressed. Heterochromatin involves a very tight association between the DNA and histones (Allis et al. 2007). For example, a compacted heterochromatic DNA structure is needed during meiosis for the chromosomes to align and recombine efficiently. Euchromatin is chromatin that is transcriptionally active and contains DNA bound loosely to histones (Allis et al. 2007). Relaxed, euchromatic structures are needed throughout the majority of spermatogenesis, or at least up until the elongated spermatid stage of spermatogenesis, in order to orchestrate the temporal expression of mRNAs that underlie the changes in nuclear and cytoplasmic morphology of the germ cells.

\section{DNA methylation}

DNA methylation is one of the most well-studied epigenetic genomic modifications. DNA methylation involves the transfer of a methyl group to the fivepositioned carbon of a cytosine within a CpG dinucleotide (Nakao 2001, Aapola et al. 2004; Table 1). Approximately $60-90 \%$ of all CpG sequences in the genome are methylated, while unmethylated $\mathrm{CpG}$ dinucleotides are mainly clustered in the CpG-rich

Table 1 Types of epigenetic modifications and their generalised functions.

\begin{tabular}{ll}
\hline Epigenetic modification & Role in transcription \\
\hline DNA methylation & Gene repression \\
Histone methylation & Gene repression and activation \\
Histone demethylation & Gene repression and activation \\
Histone acetylation & Gene activation \\
Histone deacetylation & Gene repression \\
Histone phosphorylation & Gene activation and repression \\
Histone ubiquitylation & Gene repression and activation \\
Histone sumoylation & Gene repression \\
\hline
\end{tabular}

Reproduction (2008) 136 131-146 sequence, termed $\mathrm{CpG}$ island, of the gene promoter region ( $\mathrm{Ng} \&$ Bird 1999). DNA methylation at promoter regions is involved with gene silencing. DNA methylation is also used to silence retrotransposons and imprinted genes (see below).

DNA methylation is performed by a group of proteins termed DNA (cytosine-5) methyltransferases (DNMTs). In the mouse, there are four methyltransferases: DNMT1, DNMT2 and the two closely related methyltransferases DNMT3A and DNMT3B (reviewed in Goll \& Bestor 2005). DNMT3A and DNMT3B are de novo enzymes that establish methylation patterns. DNMT1 is a maintenance enzyme involved in preserving methylation patterns already acquired (Table 2). DNMT2 has been found to methylate RNA in humans (Goll et al. 2006). It is unknown whether it has a similar role in the mouse. The mouse and several other species, including humans, also contain a closely related sequence, DNMT3L. DNMT3L lacks a catalytic domain, but can interact with both DNMT3A and DNMT3B (Ooi et al. 2007). Both in vitro and in vivo studies have shown that DNMT3L facilitates the de novo methyltransferase activity of DNMT3A (Nimura et al. 2006, Suetake et al. 2006). There is a lack of data showing that DNMT3L stimulates DNMT3B; however, in vitro studies have shown that interactions occur between the two proteins (Suetake et al. 2004).

\section{Histone modifications}

Histone modifications are essential during many cellular processes including mitosis and spermatogenesis. They assist in the formation of either condensed heterochromatic states or open euchromatic states. Histones are composed of a globular domain and amino-terminal extensions known as histone tails. Histone tails contain residues that can be post-translationally modified by methylation, acetylation, phosphorylation, ubiquitylation and sumoylation (reviewed in Lachner \& Jenuwein 2002, Fuks 2005; Fig. 2). These post-translational modifications (PTMs) alter chromatin structure thereby allowing the underlying gene to be activated or repressed.

Methylation is one of the most common histone modifications. There are several arginine and lysine residues in the $\mathrm{N}$-termini of histones that are known to be methylated (Lachner et al. 2003; Fig. 2). Histone methylation is mediated by histone methyltransferases (HMTases). Histone arginine methylation is involved in both gene activation and silencing (reviewed in Berger 2002; Table 1). Lysine residues can be mono-, di- and trimethylated and have been associated with both transcriptional silencing and activation during spermatogenesis (reviewed in Lachner \& Jenuwein 2002; Table 1). Histone demethylases mediate the removal of methyl groups from both arginine and lysine residues and are involved in both gene activation and silencing 
Table 2 Testis phenotypes of mouse models with epigenetic regulators knocked-out.

\begin{tabular}{|c|c|c|c|}
\hline Gene/protein & Function & Phenotype & References \\
\hline Dnmt3l & Facilitates DNA methylation & $\begin{array}{l}\text { Deficient pairing of homologous chromosomes } \\
\text { at the zygotene stage. Loss of germ cells evident } \\
\text { at } 6 \text { days post partum. Increased } \\
\text { retrotransposon expression from the gonocyte } \\
\text { stage. Loss of paternal imprints. }\end{array}$ & $\begin{array}{l}\text { Bourc'his \& Bestor, (2004), } \\
\text { Webster et al. (2005) and La Salle } \\
\text { et al. (2007) }\end{array}$ \\
\hline Dnmt1 & DNA methylation & $\begin{array}{l}\text { Loss of genomic methylation, improper } \\
\text { expression of imprinted genes and increased } \\
\text { expression of the IAP transposons in mutant } \\
\text { embryos. }\end{array}$ & $\begin{array}{l}\text { Li et al. (1992), Lei et al. (1996), } \\
\text { Panning \& Jaenisch, (1996) and } \\
\text { Walsh \& Bestor (1999) }\end{array}$ \\
\hline RAD54 (Rad54l) & Chromatin remodelling & Defects in DNA DSB repair during meiosis & Essers et al. (1997) \\
\hline Suv39h1 and Suv39h2 & Histone methylation & $\begin{array}{l}\text { Chromosome pairing defects, loss of } \\
\text { spermatocytes at pachytene }\end{array}$ & Peters et al. (2001) \\
\hline G9a (Ehmt2) & Histone methylation & $\begin{array}{l}\text { Improper synaptonemal complex formation, } \\
\text { major loss of spermatocytes }\end{array}$ & Tachibana et al. (2007) \\
\hline Meisetz (Prdm9) & Histone methylation & $\begin{array}{l}\text { Deficient pairing of homologous chromosomes } \\
\text { during zygotene, impaired XY body formation }\end{array}$ & Hayashi et al. (2005) \\
\hline HR6B (Ube2b) & Histone ubiquitylation & $\begin{array}{l}\text { Major defects in meiotic prophase, } \\
\text { synaptonemal complexes do not form }\end{array}$ & Baarends et al. (2003) \\
\hline$H 2 a x(H 2 a f x)$ & Chromatin remodelling & $\begin{array}{l}\text { Impaired XY body formation leading to } \\
\text { spermatocytes arresting at the pachytene stage. }\end{array}$ & Fernandez-Capetillo et al. (2003) \\
\hline TP1 (Tnp1) and TP2 (Tnp2) & $\begin{array}{l}\text { Chromatin condensation and } \\
\text { remodelling }\end{array}$ & $\begin{array}{l}\text { Major abnormalities in condensation of sperm } \\
\text { nuclei, presence of DNA strand breaks in } \\
\text { spermatids }\end{array}$ & Zhao et al. (2004) \\
\hline Prm1 or Prm2 & Chromatin compaction & $\begin{array}{l}\text { In the haploinsufficient state, morphologically } \\
\text { abnormal sperm (e.g. elongated heads) are } \\
\text { produced with altered sperm chromatin } \\
\text { integrity. }\end{array}$ & Cho et al. (2003) \\
\hline Camk4 & Protamine phosphorylation & $\begin{array}{l}\text { Impairment of spermiogenesis due to loss of } \\
\text { elongating spermatids and spermatozoa in } \\
\text { the testis. }\end{array}$ & Wu et al. (2000) \\
\hline Snf2h (Smarca5) & Chromatin remodelling & $\begin{array}{l}\text { In the haploinsufficient state, a loss of } \\
\text { methylation at the } A^{v y} \text { IAP retrotransposon in } \\
\text { wild-type offspring. }\end{array}$ & Chong et al. (2007) \\
\hline Jhdm2a (Jmjd1a) & Histone demethylation & $\begin{array}{l}\text { Post-meiotic germ cells display chromatin } \\
\text { condensation defects. Reduced expression } \\
\text { of Tnp1 and Prm1. }\end{array}$ & Okada et al. (2007) \\
\hline
\end{tabular}

(reviewed in Agger et al. 2008; Table 1). The HMTases suppressor of variegation 3-9 homolog 1 (SUV39H1) and SUV39H2, the methylation of histones $\mathrm{H} 3$ and $\mathrm{H} 4$, and the demethylation of histone $\mathrm{H} 3$ are crucial during spermatogenesis; these modifications will be discussed later in this review.

Histone acetyltransferases (HATs) can acetylate specific lysine residues in the $\mathrm{N}$-termini of all core histones and are associated with gene activation (An 2007; Table 1, Fig. 2). Histone deacetyltransferases reverse the action of HATs and are associated with gene repression (Table 1). The acetylation and deacetylation of several lysine residues on histones $\mathrm{H} 3$ and $\mathrm{H} 4$ are important during male meiosis and will be discussed later in this review.

Histone phosphorylation occurs on several serine residues of all the histones and is generally associated with transcriptional activation (reviewed in Berger 2002; Table 1, Fig. 2). By contrast, phosphorylation of the histone variant $\mathrm{H} 2 \mathrm{AX}$ (forming $\gamma \mathrm{H} 2 \mathrm{AX}$ ) correlates with chromosome condensation and gene silencing during male meiosis (Fernandez-Capetillo et al. 2003; Table 1).

Ubiquitylation on specific lysine residues can either enhance or repress transcription (reviewed in Conaway et al. 2002; Table 1). Ubiquitylation is the modification of a protein by the covalent attachment of an ubiquitin monomer to lysine residues. Histone $\mathrm{H} 2 \mathrm{~A}$ can be monoubiquitylated and its presence is linked to transcriptional repression during male meiosis (Baarends et al. 2005; Fig. 2). Conversely, H2B mono-ubiquitylation is linked to transcriptional activation (Zhu et al. 2005; Fig. 2).

Histone lysine residues may also be sumoylated and have been linked to gene repression (Shiio \& Eisenman 2003; Table 1). Sumoylation involves the covalent attachment of small ubiquitin-related modifier (SUMO) proteins to lysine residues (Shiio \& Eisenman 2003). Sumoylation generally prevents the activation of PTMs such as acetylation. There are four known SUMO proteins (SUMO1-4). To date, SUMO1 is the only one associated with spermatogenesis specifically, in silencing the XY body during meiosis (Rogers et al. 2004).

\section{ATP-dependent chromatin remodelling}

Unlike DNA methylation and histone PTMs, ATPdependent chromatin remodelling complexes are correlated with non-convalent chromatin remodelling. 


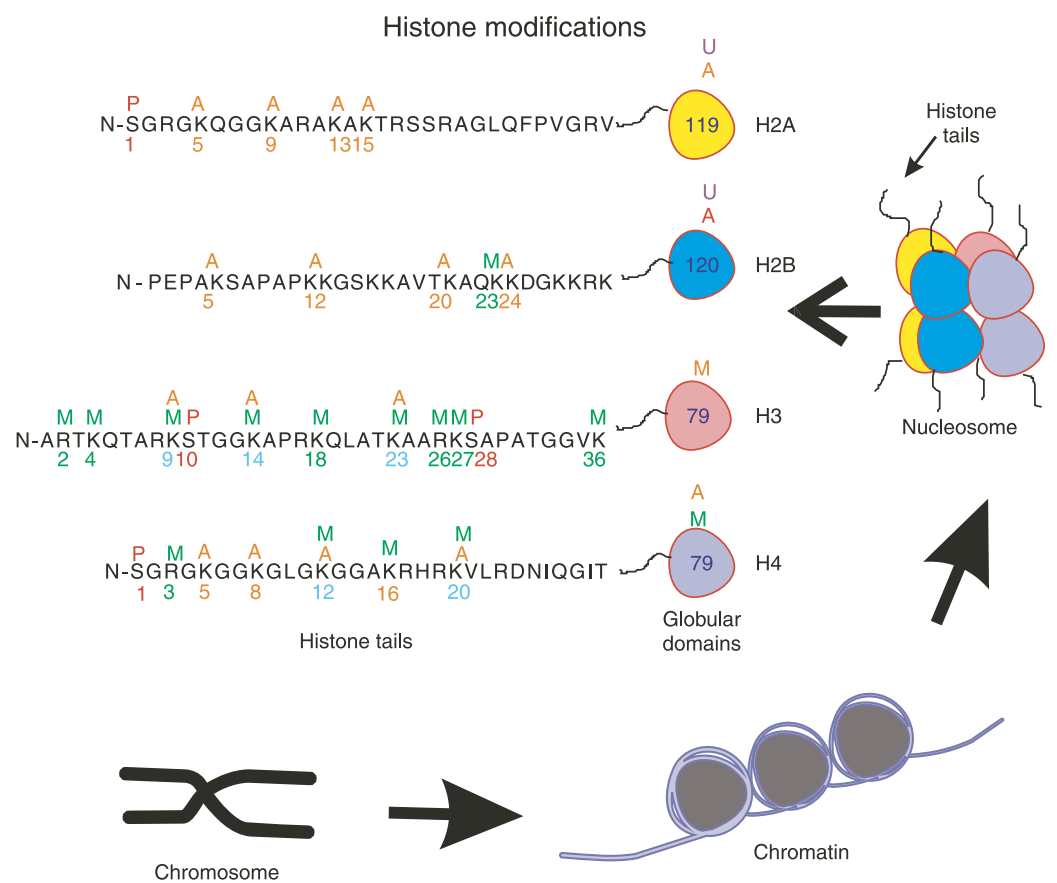

Figure 2 Histone tail modifications. Some arginine residues $(\mathrm{R})$ can be methylated. Some lysine residues $(K)$ can be either acetylated, methylated or ubiquitylated. Some serine residues (S) can be phosphorylated. Acetylation, orange; methylation, green; phosphorylation, red; ubiquitylation,

M - Methylation

A - Acetylation

$U$ - Ubiquitylation purple.

ATP-dependent complexes use the energy of ATP hydrolysis to change the position or structure of the nucleosomes and therefore affect the accessibility of transcription factors and other regulatory elements to the DNA (reviewed in Narlikar et al. 2002). ATP-dependent chromatin remodelling has been implicated in both transcriptional activation and repression. The predominant mechanism of ATP-dependent chromatin remodelling involves sliding the histones along the DNA. In addition, these complexes may twist, spool and bulge DNA (Fan et al. 2003). There are currently three known families of ATP-dependent chromatin remodelling complexes, the SWI/SNF (switch/sucrose nonfermenter) family, the ISWI (imitation switch) family and the MI-2 (myositis specific autoantigen 2) family, all of which are defined by the presence of a conserved catalytic ATPase subunit (Wang \& Zhang 2001, Fan et al. 2005).

It has previously been shown that Smarca5 (encoding $\mathrm{SNF} 2 \mathrm{H}$ ) from the ISWI family is expressed in the testis where it may have a role in DNA repair and recombination (Lazzaro \& Picketts 2001, Chong et al. 2007). As discussed later in this review, a hypomorphic allele of Smarca5 has been generated through an N-ethylnitrosourea (ENU) screen for epigenetic modifiers and has revealed that haploinsufficiency for Smarca5 shows paternal-specific effects on the phenotype of offspring (Chong et al. 2007; Table 2). The ablation of Smarca5 results in embryonic lethality at the peri-implantation stage (Stopka \& Skoultchi 2003). RAD54 from the SWI/SNF family has also been implicated in DNA repair during spermatogenesis. Disruption of Rad54 results in aberrant homologous recombination and DNA repair defects (Essers et al. 1997; Table 2).

\section{The epigenetic state during spermatogenesis}

Spermatogenesis is a highly regulated sequence of events that result in the formation of spermatozoa from precursor cells (Clermont 1972). There are three major phases that together constitute spermatogenesis: stem cell renewal by the process of mitosis, reduction of chromosomal number by meiosis and the metamorphic process termed spermiogenesis involving the transformation of the haploid germ cell into a spermatozoon (de Kretser \& Kerr 1994). Within male germ cells, changes in epigenetic state are critical for the silencing of transposable elements (TEs), the imprinting of paternal genes, several aspects of meiosis, post-meiotic gene silencing and DNA compaction.

\section{Transposable elements}

In the prenatal testis, the only germ cells present are gonocytes. The gonocytes proliferate for a few days and then become arrested (Huckins \& Clermont 1968). 
Shortly after birth, the gonocytes move to the basement membrane to become spermatogonia and resume proliferation (Huckins \& Clermont 1968). Spermatogonia divide by mitosis and constitute the pool of stem cells from which meiosis and spermatogenesis proceed.

Prior to spermatogenesis the silencing of TEs takes place in the gonocytes and prospermatogonia. TEs are pieces of mobile DNA and include DNA transposons, long terminal repeat (LTR) retrotransposons, long interspersed nuclear elements (LINEs) and short interspersed nuclear elements (reviewed in Deininger \& Batzer 2002). TEs comprise $45 \%$ of human and $37 \%$ of mouse DNA (Deininger et al. 2003). Their movement can be mutagenic and can cause chromosome breakage, improper recombination and genome rearrangement if not silenced via methylation (Deininger et al. 2003). TEs can amplify and re-insert into the genome causing ectopic activation or inactivation of genes. Normally, DNA methylation is established in the gonocytes to silence TEs thereby preventing propagation.

DNMT3L facilitated methylation is involved in the silencing of TEs in the testis as evidenced by an absence of DNMT3L causing a loss of methylation at LINE-1 and the intracisternal A-particle (IAP) transposons (Bourc'his \& Bestor 2004, Webster et al. 2005, Hata et al. 2006; Table 2). Consistent with such a role, DNMT3L is expressed in the gonocytes at 14-18 days post-coitum (dpc) when global DNA methylation is occurring (Bourc'his \& Bestor 2004). Indeed, it has been proposed that the absence of TE silencing in this model contributes directly to meiotic arrest and infertility in the adult mouse.

\section{Paternal imprinting}

Paternally imprinted genes are genes that are subject to monoallelic expression. That is, expression occurs only from the allele inherited from the maternal parent. Paternally imprinted genes are methylated, and silenced, in male germ cells. Paternal imprinting of genes starts to be established in the gonocytes at about $15.5 \mathrm{dpc}$, and continues on into the spermatogonia (Fig. 3). This methylation and gene silencing are carried through the remainder of spermatogenesis and into any resultant sperm and offspring. Only three paternally imprinted regions, H19-lgf2, Rasgrf and Dlk1-Gtl2 have been identified to date (Davis et al. 1999, Li et al. 2004). Many more maternally imprinted genes have been identified.

In male germ cells, the establishment of the paternal imprints involves a factor named BORIS (brother of the regulator of imprinted sites; Klenova et al. 2002) and the DNA methyltransferases, DNMT3A, DNMT3B and the closely related DNMT3L (Kato et al. 2007). Deletion of Dnmt3/ results in a loss of methylation at paternally imprinted regions (Table 2). Spermatogonia deficient in Dnmt3a and Dnmt3b displayed variations in methylation patterns at paternally imprinted regions (Kato et al. 2007).
DNMT1 is also important in the imprinting process. Dnmt1-deficient embryos displayed a loss of genomic methylation to less than 30\% of that found in heterozygous or wild-type embryos; furthermore, aberrant methylation patterns were observed at paternally and maternally imprinted regions (Li et al. 1992, 1993; Table 2).

While the critical importance of appropriate paternal imprinting has been established for offspring inheriting such alleles naturally (see below), a recent paper showing an increased prevalence of abnormal methylation in a set of seven imprinted genes in infertile men with oligospermia (decreased sperm count) compared with normospermic men from infertile relationships (Marques et al. 2004, Kobayashi et al. 2007) raises the possibility that a failure of imprinting may actually cause infertility. Alternatively, the observed hypomethylation of paternally imprinted alleles may be indicative of inappropriate global methylation, and as such inappropriate gene expression. Comfortingly, the study by Kobayashi et al. (2007) suggests that at least in their study, global methylation defects had not occurred. Normally, of course, such situations would be selflimiting because of the resultant infertility; however, with increasing access to intracytoplasmic sperm injection (ICSI) there is a possibility that such hypomethylated sperm are used to conceive children wherein the affects may be much more debilitating. It should be noted, however, that at the time of writing this review this possibility was only theoretical as there is no published evidence of an increase in paternally imprinted diseases in children conceived via ICSI compared with standard in vitro fertilisation where embryos have been cultured under the same conditions.

\section{Meiosis}

Spermatogonia undergo differentiation and continuous rounds of mitosis to generate primary spermatocytes, which enter meiosis (de Kretser \& Kerr 1994). Meiosis is characterised by two cell divisions, during which chromosome numbers are halved. In the first division, primary spermatocytes duplicate DNA content then divide to become secondary spermatocytes (Clermont 1972). In the second division, secondary spermatocytes divide to become round spermatids (Clermont 1972). A large part of meiosis is spent in prophase of the first division. Prophase accounts for over $90 \%$ of the duration of meiosis and lasts about 3 weeks in the mouse (Cobb \& Handel 1998). Prophase 1 is further broken up into four stages: leptotene, zygotene, pachytene and diplotene. During leptotene of meiosis, the chromosomes start condensing and double-strand breaks (DSBs) begin forming. DSBs are essential for the recombination between all homologous chromosomes that occur later in meiosis (Roeder 1997, Cobb \& Handel 1998). During zygotene, sister chromatids begin to pair and form synaptonemal complexes (SCs). SCs are proteinaceous 


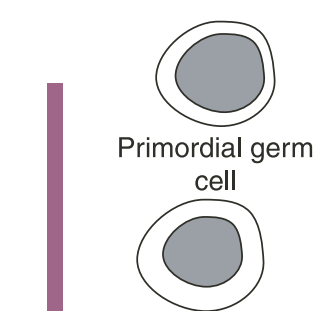

Spermatogonia

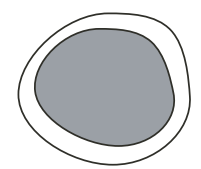

Spermatocyte

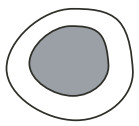

Round spermatid

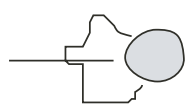

Elongating spermatid

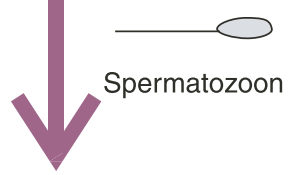

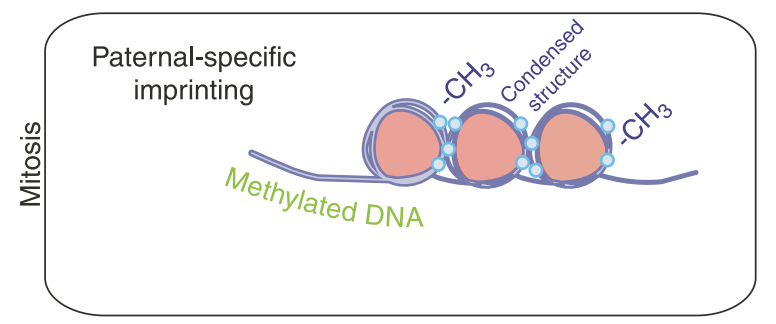
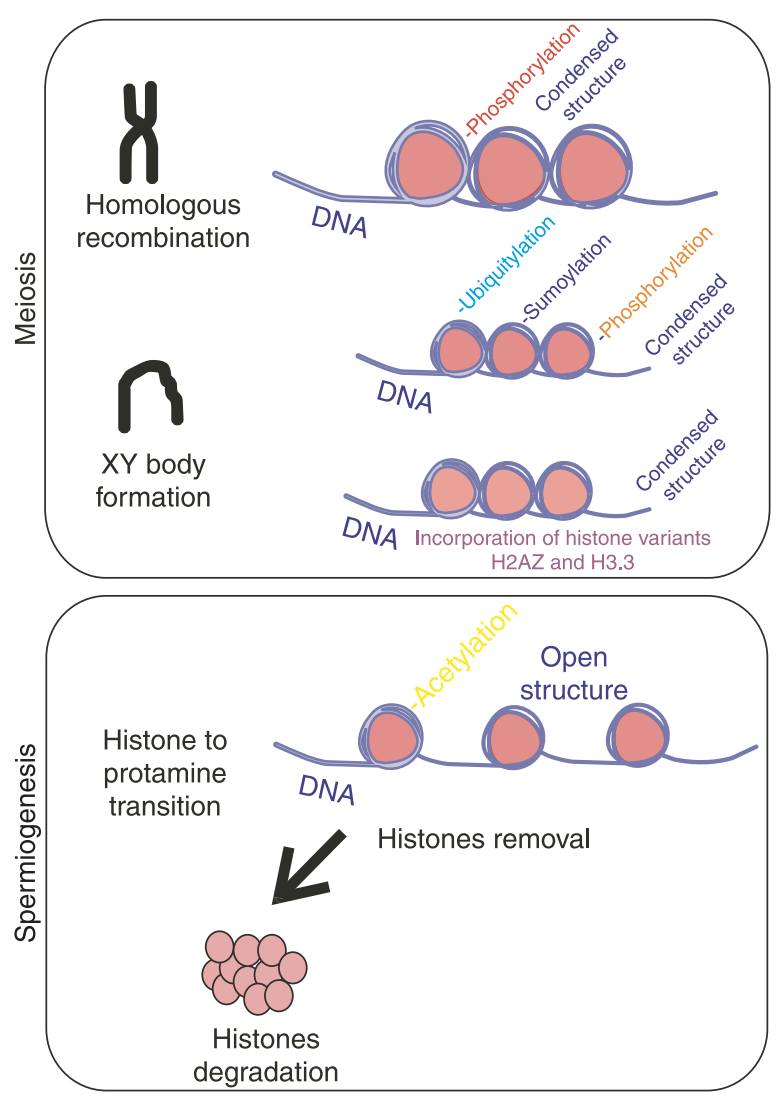

Methylated CpGs

Core histones and variants
Figure 3 Epigenetic modifications occurring during spermatogenesis. In mitotic germ cells, DNA methylation occurs to set up the paternalspecific imprints. In meiotic cells, phosphorylation occurs to assist in both recombination and $\mathrm{XY}$ body formation. Ubiquitylation, sumoylation and incorporation of the $\mathrm{H} 2 \mathrm{AZ}$ and $\mathrm{H} 3.3$ variants are all involved in $\mathrm{XY}$ body formation. Hyperacetylation occurs during spermiogenesis to assist in the histone-protamine transition. meiosis-specific structures composed of two axial elements, which form along the length of the sister chromatids and are joined by a central element which 'zips up' the two axial elements (now called lateral elements; Morelli \& Cohen 2005). Synapsis is completed during pachytene. Homologous recombination also occurs in pachytene spermatocytes. Prophase ends at diplotene when chromosome separation is initiated and SCs start disappearing (reviewed in Baarends \& Grootegoed 2003). Following prophase, the spermatocytes undergo metaphase, anaphase and telophase of the first division to produce two secondary spermatocytes per primary spermatocyte. During metaphase, the homologous chromosomes condense further and become attached to spindle fibres. The chromosomes separate, but sister chromatids remain attached and move towards opposite poles during anaphase. The spindle is squeezed and the nuclei and cytoplasm start dividing during telophase.

The secondary spermatocytes contain a single set of chromosomes but have a 2n DNA content. During the second meiotic division, the chromosomes condense and the spermatocytes undergo prophase, metaphase, anaphase and telophase of meiosis II. During meiosis II, sister chromatids separate and divide to produce round spermatids which have a $1 \mathrm{n}$ content (de Kretser \& Kerr 1994). The end products of meiosis are four haploid round spermatids per spermatocyte. Several aspects of meiosis are critically regulated by epigenetic modifications. 


\section{Chromatin remodelling and methylation during meiosis}

As evidenced in several studies, epigenetic modifications are essential for several aspects of meiotic chromosome packing, pairing and recombination (Fig. 3). DNMT3L is involved in facilitating the methylation pattern required during male meiosis. In the absence of DNMT3L, meiotic chromosomes fail to form heterochromatin appropriately and fail to pair at the zygotene stage (Bourc'his \& Bestor 2004, Webster et al. 2005; Table 3). Leptotene and zygotene spermatocytes displayed non-homologous synapsis and spermatocytes were unable to reach the full pachytene stage (Bourc'his \& Bestor 2004). As a consequence, all germ cells eventually die by apoptosis or sloughing at the zygotene-pachytene stage (Bourc'his \& Bestor 2004, Webster et al. 2005). It is believed that in Dnmt3l knockout males the loss of methylation resulted in an inappropriate euchromatic state during meiosis and genes that should be repressed, including imprinted regions, retrotransposons and repeat elements, remained active resulting in what the Bestor lab described as a 'meiotic catastrophe' (Bourc'his \& Bestor 2004, Webster et al. 2005). It is clear that DNMT3L-mediated methylation is needed for meiotic cells to progress through spermatogenesis.

The HMTases SUV39H1 and SUV39H2 have also been implicated in epigenetic regulation during male meiosis (Peters et al. 2001; Table 2). Suv39h1 is expressed in many tissues, while Suv39h2 is mainly expressed in the testis ( $\mathrm{O}^{\prime}$ Carroll et al. 2000). SUV39H1 and $\mathrm{SUV} 39 \mathrm{H} 2$ are responsible for tri-methylating lysine residue 9 on histone 3 ( $\mathrm{H} 3 \mathrm{~K} 9)$ at pericentric heterochromatic regions. $\mathrm{H} 3 \mathrm{~K} 9$ tri-methylation ( $\mathrm{H} 3 \mathrm{~K} 9 \mathrm{me} 3$ ) leads to the binding of the heterochromatin proteins $\mathrm{HP} 1 \alpha$, PP $\beta$ and HP1 $\gamma$ (Lachner et al. 2001), and the subsequent binding of the HMTase SUV420H and the methyltransferases DNMT3A/DNMT3B and the di- and tri-methylation of H4K20. Cumulatively, this leads to the establishment of a transcriptionally repressed state (Lehnertz et al. 2003, Schotta et al. 2004). Suv39hdeficient mice displayed impaired spermatogenesis. Spermatocytes undergo apoptosis in the pachytene stage as a consequence of incomplete homologue pairing and synapsis (Peters et al. 2001).

More recently, the HMTase G9A, which in somatic cells is involved in $\mathrm{H} 3 \mathrm{~K} 9$ mono- and di-methylation at euchromatic regions, has been shown to be important in male meiosis. Deletion of G9a resulted in embryonic lethality at mid-gestation, for this reason germ lineagespecific conditional G9a knockout mice were generated. These mice were sterile as spermatocytes failed to progress past the pachytene stage (Tachibana et al. 2007). Many spermatocytes were unable to form SCs. It was proposed that this perturbation in SC formation may be due to the chromosomes failing to find and pair with a homologue or to the overexpression of G9A-regulated genes (Tachibana et al. 2007).

In addition to dynamic changes in histone modifications, successful male meiosis also requires the use of specialised histone variants. The histone variant $\mathrm{H} 2 \mathrm{AX}$ is an important part of the nucleosome of meiotic cells. In response to DNA DSBs, H2AX is phosphorylated at serine residue Ser139 to form phosphorylated histone $\mathrm{H} 2 \mathrm{AX}$ ( $\gamma \mathrm{H} 2 \mathrm{AX}$; Mahadevaiah et al. 2001). On autosomes during meiosis, $\gamma \mathrm{H} 2 \mathrm{AX}$ localises to sites of DSBs and is involved in the chromatin condensation which occurs during meiotic recombination in leptotene and zygotene spermatocytes (Redon et al. 2002). It has been proposed that $\gamma \mathrm{H} 2 \mathrm{AX}$ may act to recruit members of the DNA repair machinery to DSB sites (Baarends \& Grootegoed 2003). Once DSBs disappear and synapsis is achieved, $\gamma \mathrm{H} 2 \mathrm{AX}$ is no longer localised to DSB sites.

Other DNA repair proteins that are present during meiosis are RAD50 and RAD51. RAD50 is the first to be recruited to the site of DNA DSBs on the autosomes and is present from preleptotene until the end of zygotene (Eijpe et al. 2000). RAD51 is associated with the axial elements formed during leptotene (Tarsounas \& Moens 2001). RAD54, as outlined above, is a DNA-dependent ATPase needed for recombination and DNA repair (Table 2). RAD54 interacts with RAD51 during DNA repair, together these proteins are believed to promote chromatin remodelling by displacing nucleosomes during homologous recombination (Alexeev et al. 2003).

Table 3 Epigenetic modifications associated with meiotic sex chromosome inactivation (MSCl) in the mouse.

\begin{tabular}{ll}
\hline Epigenetic modification & Reference \\
\hline Ubiquitylation of histone H2A (forming uH2A) & Baarends et al. (2005) \\
Phosphorylation of histone H2AX (forming $\gamma \mathrm{H} 2 \mathrm{AX})$ & Fernandez-Capetillo et al. (2003) \\
Small ubiquitin-related modifier-1 (SUMO1) involved in sumoylation & Rogers et al. (2004) \\
Methylation of H3 (K27) & van der Heijden et al. (2007) \\
Di-methylation of H3 (K9, K27, K79) & Khalil et al. (2004) and van der Heijden et al. (2007) \\
Di-methylation of H4 (K20) & van der Heijden et al. (2007) \\
Tri-methylation of H3 (K9) & van der Heijden et al. (2007) \\
Tri-methylation of H4 (K20) & van der Heijden et al. (2007) \\
Deacetylation of H3 (K9) & Khalil et al. (2004) \\
Deacetylation of H4 (K12 and K16) & Khalil et al. (2004) \\
Acetylation of H4 (K5 and K8) & Khalil et al. (2004) \\
\hline
\end{tabular}


The ubiquitin-conjugating enzyme HR6B is also involved in DNA damage repair and has been implicated in the regulation of chromatin structure during meiotic recombination. In Hr6b knockout mice, spermatogenesis was impaired due to major changes found in the structure of the SCs. These mice also displayed an increased frequency of meiotic recombination (Baarends et al. 2003; Table 2).

\section{Meiotic sex chromosome inactivation (MSCl)}

In the pachytene stage of meiosis, the $X$ and $Y$ chromosomes form an XY (or sex) body and become transcriptionally silent in a process known as $\mathrm{MSCl}$ (Handel 2004, Turner 2007; Fig. 3). Unlike the autosomes, in males sex chromosomes are heterologous and only synapse at their pseudoautosomal regions. The development of the $X Y$ body and the maintenance of its heterochromatic state have been the focus of several recent studies (Baarends et al. 2007, van der Heijden et al. 2007). There are now a large number of known epigenetic modifications that are associated with $\mathrm{MSCl}$, although the exact order of events are unclear (Table 3). Several of these modifications and modifiers are detailed below.

During pachytene when the autosomes synapse, $\gamma \mathrm{H} 2 \mathrm{AX}$ localises to the $X Y$ body independently of DSBs occurring (Fernandez-Capetillo et al. 2003). The importance of $\mathrm{H} 2 \mathrm{AX}$ in this process is indicated in H2ax-deficient spermatocytes which are unable to form an XY body and arrest at the pachytene stage (Fernandez-Capetillo et al. 2003; Tables 2 and 3). H2AX phosphorylation is dependent on the DNA repair protein ataxia telangiectasia and Rad3 related (ATR). ATR localises to the XY body at the onset of MSCI (Turner et al. 2004). The recruitment of ATR to the XY body depends on the tumour suppressor protein breast cancer 1, early onset (BRCA1; Turner et al. 2004). Meiotic cells of mice hypomorphic for Brca1 do not undergo $\mathrm{H} 2 \mathrm{AX}$ phosphorylation and the pachytene cells do not undergo MSCl (Turner et al. 2004). H2AX phosphorylation, ATR and BRCA1 all act together to initiate MSCI. This is one of the earliest events which takes place on the $\mathrm{XY}$ body during MSCl.

In order for $\mathrm{MSCl}$ to be maintained throughout pachytene, there are many other epigenetic modifications that occur on the $X Y$ body (reviewed in Hoyer-Fender 2003, Handel 2004, Turner 2007). They include ubiquitylation of $\mathrm{H} 2 \mathrm{~A}$ (forming $\mathrm{uH} 2 \mathrm{~A}$ ), sumoylation (involving SUMO1), methylation of $\mathrm{H} 3 \mathrm{~K} 27$, di-methylation of H3K9, H4K20, H3K79 and H3K27, tri-methylation of $\mathrm{H} 3 \mathrm{~K} 9$ and $\mathrm{H} 4 \mathrm{~K} 20$, and deacetylation of H3K9, H4K12 and H4K16 (Table 3). Modifications known to be involved with gene activation such as $\mathrm{H} 4 \mathrm{~K} 5$ and H4K8 hyperacetylation are also found on the $\mathrm{XY}$ body. The exact function each performs, however, are unknown.
In addition, it is hypothesised that meiosis-induced factor containing a PR/SET domain and zinc-finger motif (MEISETZ), which is involved in $\mathrm{H} 3 \mathrm{~K} 4$ methylation, may have a role in activating genes essential for meiosis via $\mathrm{XY}$ body formation. Meisetz is expressed in the germ cells of the foetal female gonad and in the post-natal testis (Hayashi et al. 2005). Meisetz knockout males and females have an impaired DSB repair pathway and homologous chromosomes failed to pair (Hayashi et al. 2005; Table 2). Of relevance here, in the males, the sex body does not form and the spermatocytes displayed a meiotic arrest.

The appearance of the $\mathrm{H} 2 \mathrm{~A}$ variant $\mathrm{H} 2 \mathrm{AZ}$ is also associated with $\mathrm{MSCl}$ in very late pachytene spermatocytes when many other heterochromatic marks are disappearing from the XY body (Greaves et al. 2006). At the completion of $\mathrm{MSCl}, \mathrm{H} 2 \mathrm{AZ}$ is incorporated into the $X Y$ body where it is thought to at least partially maintain the inactive state of the $X Y$ body in round and elongating spermatids (Greaves et al. 2006).

The $\mathrm{H} 3$ histone variant $\mathrm{H} 3.3$ has been implicated in $\mathrm{MSCl}$. H3.3 is incorporated into the $\mathrm{XY}$ body during $\mathrm{MSCl}$ and coincides with the loss of not only the histone variants $\mathrm{H} 3.1$ and $\mathrm{H} 3.2$ but also most of the histone PTMs (van der Heijden et al. 2007). PTMs, such as mono-, di- and tri-methylated $\mathrm{H} 3 \mathrm{~K} 4$; di- and trimethylated $\mathrm{H} 3 \mathrm{~K} 9$; mono- and di-methylated H3K27; di-methylated $\mathrm{H} 3 \mathrm{~K} 79$; and $\mathrm{di}$ - and tri-methylated $\mathrm{H} 4 \mathrm{~K} 20$, were all lost after H3.3 incorporation into the XY body (van der Heijden et al. 2007). In late meiotic and post-meiotic (i.e. round spermatid) stages, a select number of these histone modifications, predominantly those involved in gene silencing, are re-acquired (van der Heijden et al. 2007). H3.3 is known to be associated with modifications involved in gene activation including acetylation of K9, K14 and K18 (McKittrick et al. 2004). The exact role $\mathrm{H} 3.3$ performs in $\mathrm{MSCl}$ is unclear, although it is evident that $\mathrm{H} 3.3$ incorporation into the $\mathrm{XY}$ body promotes extensive chromatin remodelling and is essential for gene silencing on the $X Y$ body during the later stages of $\mathrm{MSCl}$ and the post-meiotic stages of spermatogenesis (van der Heijden et al. 2007).

In addition, SCMH1 (the mammalian homologue of Drosophila sex comb on midleg) has recently been shown to be important in regulating some of the chromatin modifications on the $\mathrm{XY}$ body. SCMH 1 is part of the mammalian Polycomb repressive complex 1 (PRC1) and is involved in the repression of numerous genes (Levine et al. 2002). Within the testis, SCMH1 is expressed in the zygotene-pachytene spermatocytes and round spermatids where it is involved in the exclusion of the PRC1 complex from the XY body. As illustrated by a recent $S c m h 1$ knockout mouse line (missing the SPM domain), a loss of $S c m h 1$ leads to male sub-fertility characterised by a loss of spermatocytes by apoptosis (Takada et al. 2007). Scmh1-deficient pachytene spermatocytes failed to maintain exclusion of the PRC1 
complex from the $X Y$ body leading to the $X Y$ body H3K27me3. Interestingly, a double knockout of Scmh1 and $P h c 2$ (another polycomb protein) corrected this phenotype. SCMH1 binds to PHC2, via its SPM domain (Isono et al. 2005). These data indicate the SCMH1 is a key regulatory component of the PRC1 in maintaining exclusion from the XY body. PHC2 on the other hand may promote such an association (Takada et al. 2007). Gene expression data also indicated that inappropriate PRC1 exclusion from the XY body did not affect $\mathrm{MSCl}$ (Takada et al. 2007).

\section{Post-meiotic sex chromosome repression (PMSR)}

It is now evident that at least partial XY body silencing persists after meiosis in a process known as PMSR (Namekawa et al. 2006). Through microarray studies focusing on X chromosome-linked genes, Namekawa etal. (2006) found that $87 \%$ of 676 genes on the $X$ chromosome remain suppressed post-meiotically. This was comparable with pachytene spermatocytes where $92 \%$ of genes were repressed. Many studies have found that modifications associated with a heterochromatic state such as trimethylation of $\mathrm{H} 3 \mathrm{~K} 9$ and deacetylation of $\mathrm{H} 3 \mathrm{~K} 9$ and H4K12 remain on the sex chromosomes post-meiotically (Khalil et al. 2004, van der Heijden et al. 2007). It has been suggested that this silencing persists into the zygote; that is, the paternally inherited $X$ chromosome $(X p)$ is preinactivated in female pre-implantation embryos (Huynh \& Lee 2003). This theory is, however, hotly debated by others who propose that the Xp is not pre-inactivated, but rather is inactivated solely within the zygote by expression of the Xist gene (Okamoto et al. 2005).

\section{Spermiogenesis}

In addition to extensive cytoplasmic metamorphoses, during this post-meiotic phase the haploid round spermatids undergo extensive chromatin remodelling to develop into mature spermatozoa (Fig. 3). This involves re-shaping and condensation of the nucleus to transcriptionally inactivate and protect the DNA. This is assisted by DSBs and the histone-to-protamine transition (reviewed in Doenecke et al. 1997, Govin et al. 2004).

The histone-to-protamine transition involves the replacement of the histones with transition nuclear proteins (TP1 and TP2), then subsequently the replacement of the TPs with protamines (PRM1 and PRM2). The histone-to-protamine transition is associated with hyperacetylation of histone H4 (Sonnack et al. 2002). Hyperacetylation promotes a looser nucleosomal structure, which allows for easy removal of the histones and incorporation of the TPs and subsequently the protamines (Sonnack et al. 2002; Fig. 3).

The replacement of histones for TPs then PRMs is essential as evidenced in several gene knockout models.
Mice lacking either TP1 or TP2 have subtle abnormalities in chromatin condensation during spermiogenesis and were fertile with normal numbers of sperm (Yu et al. 2000, Zhao et al. 2001). However, mice lacking both TPs exhibited irregular chromatin condensation in all spermatids, many showed DNA breaks, PRM2 was not post-translationally processed and male mice were sterile (Zhao et al. 2004; Table 2).

Protamines are small basic proteins rich in arginine and cysteine and are found only in spermatids (reviewed in Wouters-Tyrou et al. 1998). Most mammals produce two forms of protamine, PRM1 and PRM2, which are responsible for the DNA being packaged into a very compact arrangement. Disruption of one copy of either gene, i.e. haploinsufficiency for either $P R M 1$ or $P R M 2$, disrupts nuclear formation, processing of PRM2 and sperm function (Cho et al. 2003; Table 2). Consequently, heterozygous males were sterile. The importance of protamines is also evident in humans where an absence of PRM2 or changes in the PRM1 to PRM2 ratio in the sperm have been associated with male infertility (Balhorn et al. 1988, de Yebra et al. 1993).

The importance of protamines and their regulation for fertility is further evidenced in the Jhdm2a knockout mouse line. Protamine expression is at least in part regulated by the $\mathrm{H} 3 \mathrm{~K} 9 \mathrm{me} 2 / \mathrm{H} 3 \mathrm{~K} 9 \mathrm{me} 1$ demethylase JmjC-domain-containing histone demethylase 2A (JHDM2A). Expression of JHDM2A starts in the late pachytene stage and persists until the elongated spermatid period. Sperm do not contain JHDM2A (Okada et al. 2007). Disruption of Jhdm2a caused postmeiotic chromatin condensation defects including elongating spermatids with abnormal nuclear structure and elongation (Okada et al. 2007; Table 2). As a result, mutant males had reduced sperm counts and were infertile (Okada et al. 2007). JHDM2A functions to demethylate mono- and di-methylated $\mathrm{H} 3 \mathrm{~K} 9$ in the promoter regions of Tnp1 and Prm1 in round spermatids (Okada et al. 2007). An absence of JHDM2A results in promoter hyper-methylation and gene silencing and a lack of TP1 and PRM1, and infertility.

As indicated above, TP and PRM function, and as a consequence spermiogenesis, is regulated by epigenetic modifications. The loss of calmodulin-dependent protein kinase IV (CAMK4)-dependent serine/threonine phosphorylation of PRM2 results in sterility (Wu et al. 2000). Camk4 knockout spermatids showed a loss of PRM2 and prolonged retention of TP2 (Wu et al. 2000). As a consequence, Camk 4 knockout males were infertile and displayed a reduced number of late elongating spermatids and no mature sperm in the epididymides (Wu et al. 2000; Table 2).

In addition to the histone to protamine transition, spermiogenesis is critically dependent on changes in $\mathrm{H} 1$ linker histones. H1T2 is a H1 variant specifically expressed in round through to elongated spermatids (Martianov et al. 2005, Tanaka \& Baba 2005). 
Knockout males were sterile, or severely sub-fertile, and epididymal sperm showed abnormal morphology, cytoplasmic retention and impaired motility. Interestingly, sperm showed only trace amounts of PRM1 and PRM2 suggesting that H1T2 is also involved in the histone to protamine transition (Martianov et al. 2005, Tanaka \& Baba 2005).

At least two other $\mathrm{H} 1$ variants are also involved in spermiogenesis. H1T, which is a testis-specific variant, is first detected in pachytene spermatocytes where it is integrated into the genome and replaces the majority of somatic $\mathrm{H} 1$ linker histones. H1T is not detected beyond the early elongating spermatid stage concordant with its replacement by TPs and PRMs (Meistrich et al. 1985, Yan et al. 2003). Despite such a compelling expression pattern, an absence of $\mathrm{H} 1 \mathrm{~T}$ in the $\mathrm{H} 1 \mathrm{t}$ knockout line did not result in male infertility, suggesting that H1T does not significantly affect chromatin structure or that there is redundancy with other $\mathrm{H} 1$ testis variants (Lin et al. 2000).

HILS1 is another $\mathrm{H} 1$ linker histone variant that is detected within elongating spermatids. HILS1 protein localisation within elongating spermatids overlaps only minimally with H1T, but substantially with the TPs and PRMs (Yan et al. 2003, Iguchi et al. 2004). At least one study indicates that decreased HILS1 expression in sperm is associated with asthenozoospermia (Jedrzejczak et al. 2007).

\section{Transgenerational epigenetic inheritance}

During gametogenesis and following fertilisation, epigenetic reprogramming occurs involving the erasing and resetting of DNA methylation at imprinted loci, TEs and repeat sequences in the genome (reviewed in Morgan et al. 2005). During germ cell development, it was originally thought that all epigenetic marks were erased in the early primordial germ cells and re-established in the early gonocytes (Monk et al. 1987). Following fertilisation, it was generally held that the paternal genome is reprogrammed and epigenetic marks are again erased and reset (Oswald et al. 2000). It is now clear that epigenetic marks are not always cleared between generations and as a result epigenetic marks can be inherited. This is known as transgenerational epigenetic inheritance and it provides an additional level of phenotypic variability between individuals. It has recently been shown that several genes show transgenerational epigenetic inheritance through the male germ line (Chong et al. 2007).

The existence of transgenerational epigenetic inheritance has been most conclusively demonstrated using the agouti viable yellow $\left(A^{v y}\right)$ mouse model (Bultman et al. 1992, Morgan et al. 1999). The agouti gene is responsible for the production of yellow pigment in hair and is normally controlled by a promoter which is active at only one stage in the hair growth cycle resulting in a yellow band on black hair (Bultman et al. 1992). In the $A^{v y}$ line, a retrotransposon IAP has integrated upstream of the agouti promoter (Duhl et al. 1994; Fig. 4A). As a consequence, expression at the $A^{v y}$ locus is controlled by the LTR of the IAP retrotransposon. When the IAP retrotransposon is unmethylated, and therefore active, it overrides the endogenous promoter and results in constitutive agouti production which is visible as yellow fur. The IAP retrotransposon can be silenced (methylated), resulting in the production of agouti using the endogenous promoter and therefore brown fur. Genetically identical littermates carrying the $A^{v y}$ allele display variable expressivity of the agouti gene ranging from completely yellow to brown depending on the methylation state of the IAP in the promoter (Morgan et al. 1999; Fig. 4B). Indeed, the agouti gene within different cells can be differentially methylated to produce mottled mice. The coat colour phenotype of the mice can be classified by a trained observer as either yellow, mottled or agouti.

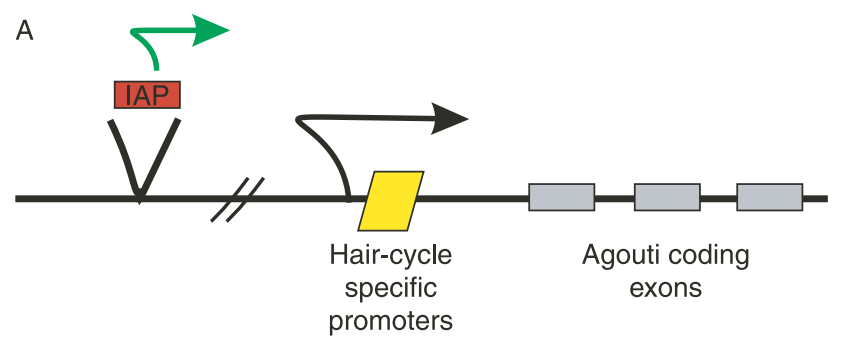

B

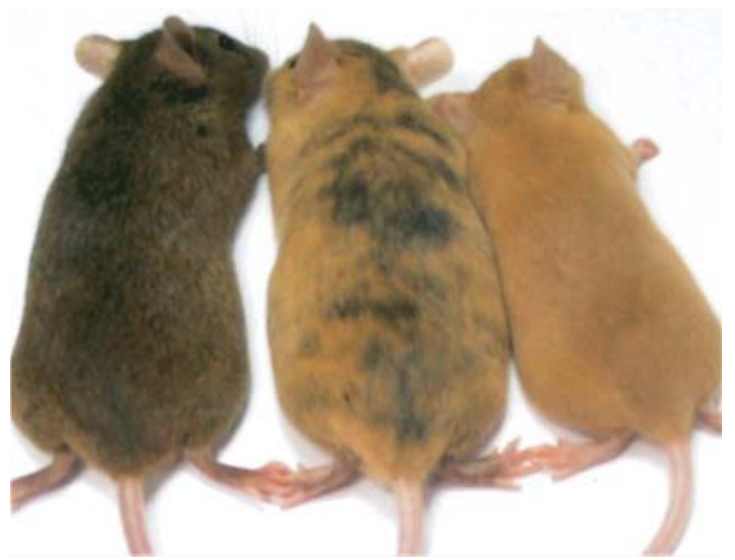

Figure 4 Agouti viable yellow allele. (A) Map of the $A^{v y}$ allele. $A^{v y}$ has an IAP (red box) inserted into the locus upstream of the agouti gene. Transcription originating in a cryptic promoter (green arrowhead) in the LTR of the IAP drives constitutive expression of $A^{v y}$ when it is active, leading to yellow coat colour. When this cryptic promoter is silenced, expression of $A^{v y}$ occurs under the control of hair-cycle specific promoters, leading to brown coat colour. (B) Range of phenotypes in isogenic $A^{v y}$ mice. Yellow mice have agouti expression driven by the inserted IAP. Mottled mice display variegation, some cells have expression driven by the IAP and some lack this expression. Agouti mice lack expression from the cryptic promoter, $A^{v y}$ is regulated by hair-cycle specific promoters, these mice have the brown coat colour. 
The $A^{v y}$ allele shows parent-of-origin effects where the range of coat colours depends on whether $A^{v y}$ is inherited from the mother or father. When $A^{v y}$ is transmitted by a yellow $A^{v y}$ dam, her offspring are more likely to be yellow than agouti (Morgan et al. 1999). This effect is not seen through paternal transmission. It was proposed that this maternal epigenetic effect resulted from incomplete clearing of epigenetic marks at the $A^{v y}$ allele leading to inheritance of the epigenetic modification (Morgan et al. 1999). Maternal and paternal epigenetic inheritance has also been observed at the axin-fused $\left(A x i n^{F u}\right)$ allele, another gene where expression is controlled by the LTR of an IAP retrotransposon (Rakyan et al. 2003).

\section{Paternal effect genes in mice}

The existence of mammalian paternal effect genes has also been recently confirmed. This was done via an ENU mutagenesis screen to identify regulators of the epigenetic state; specifically mutations that would alter the methylation status of a blood expressed transgene (Blewitt et al. 2005). This screen identified a mouse line carrying a point mutation in Smarca5: Smarca5 $5^{\text {MommeD4 }}$ (modifiers of murine metastable epialleles D4). This mutation not only resulted in altered expression of the transgene, but also displayed a paternal-specific transgenerational effect on the phenotype of the offspring (Chong et al. 2007). Paternal effect genes had previously been reported in $D$. melanogaster but had not previously been identified in mammals (Fitch et al. 1998).

Specifically, when Smarca5 heterozygous males were mated to yellow $A^{v y}$ heterozygous females, heterozygous offspring were more likely to be brown than their wildtype littermates (Blewitt et al. 2005). This suggested an increased incidence of methylation at the IAP retrotransposon associated with the $A^{v y}$ allele in these offspring and is consistent with Smarca5 being an enhancer of variegation (Fig. 5). As an extension of this, Chong et al. (2007) observed that the range of coat colours of wild-type offspring produced from a Smarca5 heterozygous male was different to the range seen in wild-type offspring from a Smarca5 wild-type male (Table 2). The wild-type offspring produced from the heterozygous fathers were more likely to be yellow than the wild-type offspring produced from the wild-type fathers (Chong et al. 2007; Fig. 5). This is consistent with hypomethylation of the IAP retrotransposon in wild-type pups from heterozygous fathers and suggests that while the majority of paternally inherited epigenetic modifications are erased in the zygote, not all are.

As such, Smarca5 is a paternal effect gene; that is, a gene in which a mutation in the male parent affects the phenotype of wild-type offspring. This affect was not seen in pups from Smarca5 heterozygous dams. Wildtype offspring from the Smarca5 heterozygous and wild-type fathers were genetically identical (isogenic).
The only difference was that one group was sired by a Smarca5 heterozygous male and the other from a wildtype male. Thus, the wild-type offspring produced from the heterozygous fathers were maintaining an epigenetic memory of their father's genotype. A similar result was observed with a hypomorphic allele of Dnmt1 (termed Dnmt $1^{\text {MommeD2}}$ ) produced in the same ENU screen (Chong et al. 2007). This provides evidence that the epigenetic state of the paternal germ line may have a significant affect on the phenotype of offspring independently of the transmitted genotype. The number of paternal effect genes in the whole genome is currently unknown.

Transgenerational paternal effects of another type have been observed in the Dnmt3/ knockout mouse line. In the Dnmt3/ knockout mouse line, when heterozygous males were mated to wild-type females, spontaneous $\mathrm{X}$ chromosome aneuploidy $(\mathrm{XO})$ occurred with an increased frequency in offspring. Humans with an XO chromosome content have Turner's syndrome and are outwardly female, but have early degeneration of the ovaries and oestrogen insufficiency. They usually have short stature and may have a high arched palate, neck webbing, broad chest, cardiac and renal abnormalities, impaired cognitive skills and spatial intelligence (Skuse 2005).

When Dnmt3/ heterozygous males were mated to wild-type females the frequency of XO offspring was 2$2.4 \%$, depending on genetic background, compared with $0 \%$ from wild-type males (Chong et al. 2007). Out of the three Dnmt3/ XO offspring studied, two had lost the paternal $X$ or $Y$ chromosome while one had lost the maternal $X$ chromosome. The loss of the paternal $\mathrm{X}$ or $\mathrm{Y}$ chromosome suggested that the loss occurred either in the male germ line during spermatogenesis or post-fertilisation, while the loss of the maternal $X$ chromosome suggested that the $\mathrm{X}$ chromosome is lost post-fertilisation (Chong et al. 2007). The occurrence of $\mathrm{XO}$ in the Dnmt3/ mouse line suggests a previously unrecognised role for DNMT3 $L$ in regulating $X$ chromosome alignment and segregation during meiosis and of the epigenetic state in general in the generation of aneuploid gametes. Aneuploidy in humans occurs in at least $5 \%$ of all live births and probably accounts for a large number of miscarriages (Lamb \& Hassold 2004). These data suggest that hypomorphic epigenetic modifiers in a potential father may be a cause of sub-fertility. Clearly, this is an area of research that requires additional work.

\section{Evidence of transgenerational effects of environmental factors on the germ line in rodents}

The effects described above are only thought to affect a potential father and his immediate offspring. However, several recent animal studies have suggested that embryonic exposure to some environmental factors 


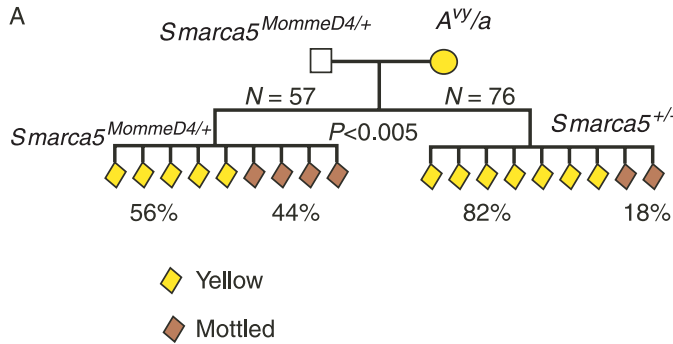

B

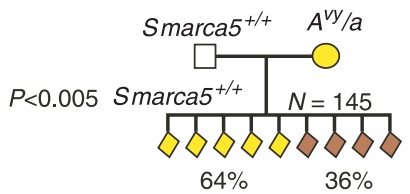

Figure 5 Pedigrees produced from Smarca5 heterozygous males and Smarca5 wild-type males. (A) Pedigree produced from Smarca5 heterozygous males and yellow $A^{v y}$ heterozygous females. When sired by a heterozygous father, offspring heterozygous for Smarca5 demonstrated a shift in penetrance at $A^{v y}$ towards mottled when compared with wild-type littermates $(P<0.005)$. (B) Pedigree produced from Smarca5 wild-type males and yellow $A^{v y}$ heterozygous females. The coat colour phenotypes of wild-type offspring from a wild-type sire were compared with the wild-type offspring from a Smarca5 heterozygous sire. Wild-type offspring from Smarca5 heterozygous sires showed a significant increase in the proportion of offspring with yellow coats when compared with the wild-type offspring from wild-type sires.

can result in diseases which may be inherited across multiple generations. For example, feeding pregnant rats a protein-restricted isocaloric diet increases the incidence of diabetes in the $\mathrm{F}_{2}$ progeny (Zambrano et al. 2005). In utero and lactational exposure of the environmental chemical dioxin in rats affects the development of male gonads in offspring $\left(\mathrm{F}_{1}\right)$, leading to changes in the sex ratio (reduction in male pups) of the subsequent generation ( $F_{2}$; Ikeda et al. 2005).

While it is clear that exposure of the grandmother in these circumstances did have affects on the grandchild, these affects could all be directly due to the initial exposure; that is, the foetus and its primordial germ cells were all directly exposed via the mother's (or grandmother's) circulation. For a compound or incident to truly have a transgenerational affect it should affect at least the $\mathrm{F}_{3}$ generation. There is some evidence that such situations do occur. For example, exposure of pregnant mice to the carcinogen benzapyrene increased the risk of lung tumours in not only the $F_{1}$ generation but also in the $F_{2}-F_{5}$ generations of mice (Turusov et al. 1990).

More recent studies have suggested transgenerational effects from the endocrine disruptor vinclozolin (Anway et al. 2005, Chang et al. 2006). Vinclozolin is a fungicide used on agricultural crops including in the wine industry and is an anti-androgenic (Kelce et al. 1994). Pregnant rats treated with vinclozolin at the time of gonadal sex determination (embryonic days 8-14) produced male offspring with reduced spermatogenic capacity which persisted in male offspring in the $F_{2}-F_{4}$ generations (Anway et al. 2005). When male and female progeny in the $F_{1}-F_{4}$ generations were maintained until adulthood they developed diseases or tissue abnormalities such as prostate disease, kidney disease, breast cancer, testis abnormalities and immune system abnormalities (Anway et al. 2006). These transgenerational disease states were only observed when colonies were maintained through the paternal line. When offspring were produced using an affected dam, subsequent generations of animals appeared normal.
The authors have proposed that these transgenerational affects were due to altered epigenetic state and involve aberrant regulation of the methyltransferases DNMT3A and DNMT3L (Anway et al. 2008). They propose that disease (and male sub-fertility) was the result of altered genome-wide methylation and as a consequence gene expression.

It is true to say that both the epigenetic mechanism and transgenerational consequences of vinclozolin are hotly debated. Nonetheless, these studies provide a fascinating area for future research with potentially widespread implications for public health.

\section{Evidence of transgenerational effects of environmental factors on the germ line in humans}

There are several diseases that are caused by aberrant expression of imprinted genes. These include the developmental disorders Prader-Willi syndrome (PWS), Angelman syndrome (AS) and Beckwith-Wiedemann syndrome (BWS). PWS and AS are caused by the disruption of several maternally and paternally imprinted genes located on chromosome 15 (Camprubi et al. 2007). The loss of $S N R P N$ expression is most commonly associated with PWS, while the loss of UBE3A is most commonly associated with AS. All causes of BWS to date have been associated with alterations in the methylation state of one or more imprinted genes in the $11 \mathrm{p} 15.5$ imprinted gene cluster (reviewed in Maher \& Reik 2000).

Assisted reproductive techniques (ART) have been associated with a statistically significant increased risk of AS and BWS in offspring (reviewed in Gosden et al. 2003). It is proposed that the frequency of imprinting disorders is increased as a consequence of in vitro culturing conditions, or chemical composition of the culture media, which can result in the loss of methylation on imprinted regions in either the oocyte or embryo as opposed to aberrant epigenetic state in male gametes (Khosla et al. 2001). However, as mentioned earlier, it has been recently shown that 
males with oligospermia have an increased frequency of defective methylation compared with normospermic males (Kobayashi et al. 2007). This raises the possibility that hypomethylated paternally imprinted genes may contribute to imprinting errors and disease in ARTconceived children.

Similar to the exposure of rodents to dioxins or caloric restriction, in the human populations there have been many documented cases of changes in sex ratios following chemical exposure or after a natural disaster which may be consistent with altered epigenetic state across a population. For example in 1976, the population of Seveso in Italy were exposed to the herbicide dioxin. Exposed males produced a higher percentage of female offspring (65\%) compared with male offspring (35\%; Mocarelli et al. 1996). Pesticide workers in several countries are still exposed to high levels of dioxin. An investigation conducted on Russian pesticide workers also found that male exposure to dioxin was associated with an increase in the number of female births $(62 \%$; Ryan et al. 2002). It was proposed that exposure to dioxin affected sperm production in the testis leading to changes in the sex ratio (Jongbloet et al. 2002).

Similarly, after the Kobe earthquake in Japan (Fakuda et al. 1998), the 10-day war in Slovenia (Zorn et al. 2002) and in California following the terrorist attacks of September 11 (Catalano et al. 2005) a decline in the sex ratio (male:female) at birth was observed. It has been proposed that stress related to a catastrophic event may have a negative effect on sperm production or function resulting in a decline in sex ratio (Fakuda et al. 1998, Zorn et al. 2002). Alternatively, it could be interpreted that these studies reveal paternal effects similar to those documented in rodents (Anway et al. 2005, Ikeda et al. 2005). It is of note that within these populations there is no documented evidence of elevated levels of sex reversal or infertility, suggesting that the transmission ratio distortion is a true change in X- versus Y-bearing sperm.

\section{Conclusion}

This review underscores the importance of appropriate epigenetic regulation throughout all phases of spermatogenesis. Deviation from this program can lead to infertility or consequences for subsequent generations. During male germ cell development, epigenetic regulation is crucial in TE silencing, imprinting, chromatin remodelling, $\mathrm{MSCl}$, the histone-protamine transition and PMSR. Although many of the epigenetic modifications regulating these events have been elucidated, there are still many questions to be answered. What are the exact functions of the epigenetic modifications associated with spermatogenesis? In what order do these modifications occur and what impact do these modifications have on human male fertility?
The studies discussed in this review suggest that environmental factors may influence the epigenetic state and that these epigenetic modifications may be inherited through the male germ line and passed onto more than one generation. The paternal effects described in this review have further highlighted the importance of research into epigenetic regulation and male fertility. The concept that untransmitted alleles passed through the male germ line can affect the phenotype of the next generation is a new and exciting area of research. The transgenerational and paternal effects displayed by these mice may be related to idiopathic cases of sporadic disease or infertility in humans.

\section{Declaration of interest}

The authors declare that there is no conflict of interest that would prejudice the impartiality of this scientific work.

\section{Funding}

Supported by grants from the National Health and Medical Research Council (NHMRC) and the Australian Research Council (ARC).

\section{References}

Aapola U, Maenpaa K, Kaipia A \& Peterson P 2004 Epigenetic modifications affect Dnmt3L expression. Biochemical Journal $\mathbf{3 8 0}$ 705-713.

Agger K, Christensen J, Cloos PA \& Helin K 2008 The emerging functions of histone demethylases. Current Opinion in Genetics \& Development 18 159-168.

Alberts B, Bray D, Lewis J, Raff M, Roberts K \& Watson JD 1989 Molecular Biology of the Cell. New York: Garland Publishing, Inc.

Alexeev A, Mazin A \& Kowalczykowski SC 2003 Rad54 protein possesses chromatin-remodeling activity stimulated by the Rad51-ssDNA nucleoprotein filament. Nature Structural Biology 10 182-186.

Allis CD, Jenuwein T \& Reinberg D 2007 Overview and concepts. In Epigenetics, 1 edn. Eds CD Allis, T Jenuwein \& D Reinberg. New York: Cold Spring Harbour Laboratory Press.

An W 2007 Histone acetylation and methylation: combinatorial players for transcriptional regulation. Sub-Cellular Biochemistry 41 351-369.

Anway MD, Cupp AS, Uzumcu M \& Skinner MK 2005 Epigenetic transgenerational actions of endocrine disruptors and male fertility. Science 308 1466-1469.

Anway MD, Leathers C \& Skinner MK 2006 Endocrine disruptor vinclozolin induced epigenetic transgenerational adult-onset disease. Endocrinology 147 5515-5523.

Anway MD, Rekow SS \& Skinner MK 2008 Transgenerational epigenetic programming of the embryonic testis transcriptome. Genomics $\mathbf{9 1}$ 30-40.

Baarends WM \& Grootegoed JA 2003 Chromatin dynamics in the male meiotic prophase. Cytogenetic and Genome Research 103 225-234.

Baarends WM, Wassenaar E, Hoogerbrugge JW, van Cappellen G, Roest HP, Vreeburg J, Ooms M, Hoeijmakers JH \& Grootegoed JA 2003 Loss of HR6B ubiquitin-conjugating activity results in damaged synaptonemal complex structure and increased crossing-over frequency during the male meiotic prophase. Molecular and Cellular Biology 23 1151-1162.

Baarends WM, Wassenaar E, van der Laan R, Hoogerbrugge J, SleddensLinkels E, Hoeijmakers JH, de Boer P \& Grootegoed JA 2005 Silencing of unpaired chromatin and histone $\mathrm{H} 2 \mathrm{~A}$ ubiquitination in mammalian meiosis. Molecular and Cellular Biology 25 1041-1053. 
Baarends WM, Wassenaar E, Hoogerbrugge JW, Schoenmakers S, Sun ZW \& Grootegoed JA 2007 Increased phosphorylation and dimethylation of $\mathrm{XY}$ body histones in the Hr6b-knockout mouse is associated with derepression of the $X$ chromosome. Journal of Cell Science $\mathbf{1 2 0}$ 1841-1851.

Balhorn R, Reed S \& Tanphaichitr N 1988 Aberrant protamine 1/protamine 2 ratios in sperm of infertile human males. Experientia 44 52-55.

Berger SL 2002 Histone modifications in transcriptional regulation. Current Opinion in Genetics \& Development 12 142-148.

Blewitt ME, Vickaryous NK, Hemley SJ, Ashe A, Bruxner TJ, Preis JI, Arkell R \& Whitelaw E 2005 An N-ethyl-N-nitrosourea screen for genes involved in variegation in the mouse. PNAS 102 7629-7634.

Bourc'his D \& Bestor TH 2004 Meiotic catastrophe and retrotransposon reactivation in male germ cells lacking Dnmt3L. Nature 431 96-99.

Bultman SJ, Michaud EJ \& Woychik RP 1992 Molecular characterization of the mouse agouti locus. Cell 71 1195-1204.

Camprubi C, Coll MD, Villatoro S, Gabau E, Kamli A, Martinez MJ, Poyatos D \& Guitart M 2007 Imprinting center analysis in Prader-Willi and Angelman syndrome patients with typical and atypical phenotypes. European Journal of Medical Genetics 50 11-20.

Catalano R, Bruckner T, Gould J, Eskenazi B \& Anderson E 2005 Sex ratios in California following the terrorist attacks of September 11, 2001. Human Reproduction 20 1221-1227.

Chang HS, Anway MD, Rekow SS \& Skinner MK 2006 Transgenerational epigenetic imprinting of the male germline by endocrine disruptor exposure during gonadal sex determination. Endocrinology 147 $5524-5541$.

Cho C, Jung-Ha H, Willis WD, Goulding EH, Stein P, Xu Z, Schultz RM, Hecht NB \& Eddy EM 2003 Protamine 2 deficiency leads to sperm DNA damage and embryo death in mice. Biology of Reproduction 69 211-217.

Chong S, Vickaryous N, Ashe A, Zamudio N, Youngson N, Hemley S, Stopka T, Skoultchi A, Matthews J, Scott HS et al. 2007 Modifiers of epigenetic reprogramming show paternal effects in the mouse. Nature Genetics 39 614-622.

Clermont Y 1972 Kinetics of spermatogenesis in mammals: seminiferous epithelium cycle and spermatogonial renewal. Physiological Reviews 52 198-236.

Cobb J \& Handel MA 1998 Dynamics of meiotic prophase I during spermatogenesis: from pairing to division. Seminars in Cell and Developmental Biology 9 445-450.

Conaway RC, Brower CS \& Conaway JW 2002 Emerging roles of ubiquitin in transcription regulation. Science 296 1254-1258.

Davis TL, Trasler JM, Moss SB, Yang GJ \& Bartolomei MS 1999 Acquisition of the H19 methylation imprint occurs differentially on the parental alleles during spermatogenesis. Genomics 58 18-28.

Deininger PL \& Batzer MA 2002 Mammalian retroelements. Genome Research 12 1455-1465.

Deininger PL, Moran JV, Batzer MA \& Kazazian HH Jr 2003 Mobile elements and mammalian genome evolution. Current Opinion in Genetics \& Development 13 651-658.

Doenecke D, Drabent B, Bode C, Bramlage B, Franke K, Gavenis K, Kosciessa U \& Witt O 1997 Histone gene expression and chromatin structure during spermatogenesis. Advances in Experimental Medicine and Biology 424 37-48.

Duhl DM, Vrieling H, Miller KA, Wolff GL \& Barsh GS 1994 Neomorphic agouti mutations in obese yellow mice. Nature Genetics 8 59-65.

Egger GG, Liang GG, Aparicio AA \& Jones PAPA 2004 Epigenetics in human disease and prospects for epigenetic therapy. Nature $\mathbf{4 2 9} 457$.

Eijpe M, Offenberg H, Goedecke W \& Heyting C 2000 Localisation of RAD50 and MRE11 in spermatocyte nuclei of mouse and rat. Chromosoma 109 123-132.

Essers J, Hendriks RW, Swagemakers SM, Troelstra C, de Wit J, Bootsma D, Hoeijmakers JH \& Kanaar R 1997 Disruption of mouse RAD54 reduces ionizing radiation resistance and homologous recombination. Cell 89 195-204.

Fakuda M, Fakuda K, Shimizu T \& Moller H 1998 Decline in sex ratio at birth after Kobe earthquake. Human Reproduction 13 2321-2322.

Fan HY, He X, Kingston RE \& Narlikar GJ 2003 Distinct strategies to make nucleosomal DNA accessible. Molecular Cell 11 1311-1322.

Fan HY, Trotter KW, Archer TK \& Kingston RE 2005 Swapping function of two chromatin remodeling complexes. Molecular Cell 17 805-815.
Fernandez-Capetillo O, Mahadevaiah SK, Celeste A, Romanienko PJ, Camerini-Otero RD, Bonner WM, Manova K, Burgoyne P \& Nussenzweig A $2003 \mathrm{H} 2 \mathrm{AX}$ is required for chromatin remodeling and inactivation of sex chromosomes in male mouse meiosis. Developmental Cell 4 497-508.

Fitch KR, Yasuda GK, Owens KN \& Wakimoto BT 1998 Paternal effects in Drosophila: implications for mechanisms of early development. Current Topics in Developmental Biology 38 1-34.

Fuks F 2005 DNA methylation and histone modifications: teaming up to silence genes. Current Opinion in Genetics \& Development 15 490-495.

Goldberg AD, Allis CD \& Bernstein E 2007 Epigenetics: a landscape takes shape. Cell 128 635-638.

Goll MG \& Bestor TH 2005 Eukaryotic cytosine methyltransferases. Annual Review of Biochemistry 74 481-514.

Goll MG, Kirpekar F, Maggert KA, Yoder JA, Hsieh CL, Zhang X, Golic KG, Jacobsen SE \& Bestor TH 2006 Methylation of tRNAAsp by the DNA methyltransferase homolog Dnmt2. Science 311 395-398.

Gosden R, Trasler J, Lucifero D \& Faddy M 2003 Rare congenital disorders, imprinted genes, and assisted reproductive technology. Lancet 361 1975-1977.

Govin J, Caron C, Lestrat C, Rousseaux S \& Khochbin S 2004 The role of histones in chromatin remodelling during mammalian spermiogenesis. European Journal of Biochemistry 271 3459-3469.

Greaves IK, Rangasamy D, Devoy M, Marshall Graves JA \& Tremethick DJ 2006 The $X$ and $Y$ chromosomes assemble into H2A.Z-containing [corrected] facultative heterochromatin [corrected] following meiosis. Molecular and Cell Biology 26 5394-5405.

Handel MA 2004 The XY body: a specialized meiotic chromatin domain. Experimental Cell Research 296 57-63.

Hata K, Kusumi M, Yokomine T, Li E \& Sasai H 2006 Meiotic and epigenetic aberrations in Dnmt3L-deficient male germ cells. Molecular Reproduction and Development 73 116-122.

Hayashi K, Yoshida K \& Matsui Y 2005 A histone H3 methyltransferase controls epigenetic events required for meiotic prophase. Nature $\mathbf{4 3 8}$ $374-378$.

van der Heijden GW, Derijck AA, Posfai E, Giele M, Pelczar P, Ramos L, Wansink DG, van der Vlag J, Peters AH \& de Boer P 2007 Chromosomewide nucleosome replacement and $\mathrm{H} 3.3$ incorporation during mammalian meiotic sex chromosome inactivation. Nature Genetics 39 251-258.

Hoyer-Fender S 2003 Molecular aspects of XY body formation. Cytogenetic and Genome Research 103 245-255.

Huckins C \& Clermont Y 1968 Evolution of gonocytes in the rat testis during late embryonic and early post-natal life. Archives d'Anatomie, d'Histologie et d'Embryologie Normales et Expérimentales 51 341-354.

Huynh KD \& Lee JT 2003 Inheritance of a pre-inactivated paternal X chromosome in early mouse embryos. Nature $\mathbf{4 2 6} 857-862$.

Iguchi N, Tanaka H, Yamada S, Nishimura H \& Nishimune Y 2004 Control of mouse hils1 gene expression during spermatogenesis: identification of regulatory element by transgenic mouse. Biology of Reproduction $\mathbf{7 0}$ 1239-1245.

Ikeda M, Tamura M, Yamashita J, Suzuki C \& Tomita T 2005 Repeated in utero and lactational 2,3,7,8-tetrachlorodibenzo-p-dioxin exposure affects male gonads in offspring, leading to sex ratio changes in F2 progeny. Toxicology and Applied Pharmacology 206 351-355.

Isono K, Fujimura Y, Shinga J, Yamaki M, O-Wang J, Takihara Y, Murahashi Y, Takada Y, Mizutani-Koseki Y \& Koseki H 2005 Mammalian polyhomeotic homologues Phc2 and Phc1 act in synergy to mediate polycomb repression of Hox genes. Molecular and Cell Biology 25 6694-6706.

Jedrzejczak P, Kempisty B, Bryja A, Mostowska M, Depa-Martynow M, Pawelczyk L \& Jagodzinski PP 2007 Quantitative assessment of transition proteins 1, 2 spermatid-specific linker histone $\mathrm{H} 1$-like protein transcripts in spermatozoa from normozoospermic and asthenozoospermic men. Archives of Andrology 53 199-205.

Jongbloet PH, Roeleveld N \& Groenewoud HM 2002 Where the boys aren't: dioxin and the sex ratio. Environmental Health Perspectives 110 $1-3$.

Kato Y, Kaneda M, Hata K, Kumaki K, Hisano M, Kohara Y, Okano M, Li E, Nozaki M \& Sasaki H 2007 Role of the Dnmt3 family in de novo methylation of imprinted and repetitive sequences during male germ cell development in the mouse. Human Molecular Genetics 16 2272-2280. 
Kelce WR, Monosson E, Gamcsik MP, Laws SC \& Gray LE Jr 1994 Environmental hormone disruptors: evidence that vinclozolin developmental toxicity is mediated by antiandrogenic metabolites. Toxicology and Applied Pharmacology 126 276-285.

Khalil AM, Boyar FZ \& Driscoll DJ 2004 Dynamic histone modifications mark sex chromosome inactivation and reactivation during mammalian spermatogenesis. PNAS 101 16583-16587.

Khosla S, Dean W, Reik W \& Feil R 2001 Culture of preimplantation embryos and its long-term effects on gene expression and phenotype. Human Reproduction Update 7 419-427.

Klenova EM, Morse HC III, Ohlsson R \& Lobanenkov VV 2002 The novel BORIS + CTCF gene family is uniquely involved in the epigenetics of normal biology and cancer. Seminars in Cancer Biology 12 399-414.

Kobayashi H, Sato A, Otsu E, Hiura H, Tomatsu C, Utsunomiya T, Sasaki H, Yaegashi N \& Arima T 2007 Aberrant DNA methylation of imprinted loci in sperm from oligospermic patients. Human Molecular Genetics 16 2542-2551.

de Kretser DM \& Kerr JB 1994 Cytology of the testis. In: The Physiology of Reproduction. New York: Raven Press.

Lachner M \& Jenuwein T 2002 The many faces of histone lysine methylation. Current Opinion in Cell Biology 14 286-298.

Lachner M, O'Carroll D, Rea S, Mechtler K \& Jenuwein T 2001 Methylation of histone $\mathrm{H} 3$ lysine 9 creates a binding site for HP1 proteins. Nature $\mathbf{4 1 0}$ $116-120$

Lachner M, O'Sullivan RJ \& Jenuwein T 2003 An epigenetic road map for histone lysine methylation. Journal of Cell Science 116 2117-2124.

Lamb NE \& Hassold TJ 2004 Nondisjunction - a view from ringside. New England Journal of Medicine 351 1931-1934.

Lazzaro MA \& Picketts DJ 2001 Cloning and characterization of the murine Imitation Switch (ISWI) genes: differential expression patterns suggest distinct developmental roles for Snf2h and Snf2l. Journal of Neurochemistry 77 1145-1156.

Lehnertz B, Ueda Y, Derijck AA, Braunschweig U, Perez-Burgos L, Kubicek S, Chen T, Li E, Jenuwein T \& Peters AH 2003 Suv39h-mediated histone $\mathrm{H} 3$ lysine 9 methylation directs DNA methylation to major satellite repeats at pericentric heterochromatin. Current Biology 13 1192-1200.

Lei H, Oh SP, Okano M, Jüttermann R, Goss KA, Jaenisch R \& Li E 1996 De novo DNA cytosine methyltransferase activities in mouse embryonic stem cells. Development 122 3195-3205.

Levine SS, Weiss A, Erdjument-Bromage H, Shao Z, Tempst P \& Kingston RE 2002 The core of the polycomb repressive complex is compositionally and functionally conserved in flies and humans. Molecular and Cell Biology 22 6070-6078.

Li EE, Bestor TTH \& Jaenisch RR 1992 Targeted mutation of the DNA methyltransferase gene results in embryonic lethality. Cell 69915.

Li EE, Beard CC \& Jaenisch RR 1993 Role for DNA methylation in genomic imprinting. Nature 366362.

Li JY, Lees-Murdock DJ, Xu GL \& Walsh CP 2004 Timing of establishment of paternal methylation imprints in the mouse. Genomics 84 952-960.

Lin Q, Sirotkin A \& Skoultchi AI 2000 Normal spermatogenesis in mice lacking the testis-specific linker histone H1t. Molecular and Cell Biology $202122-2128$.

Mahadevaiah SK, Turner JM, Baudat F, Rogakou EP, de Boer P, BlancoRodriguez J, Jasin M, Keeney S, Bonner WM \& Burgoyne PS 2001 Recombinational DNA double-strand breaks in mice precede synapsis. Nature Genetics 27 271-276.

Maher ER \& Reik W 2000 Beckwith-Wiedemann syndrome: imprinting in clusters revisited. Journal of Clinical Investigation 105 247-252.

Marques CJ, Carvalho F, Sousa M \& Barros A 2004 Genomic imprinting in disruptive spermatogenesis. Lancet 363 1700-1702.

Martianov I, Brancorsini S, Catena R, Gansmuller A, Kotaja N, Parvinen M, Sassone-Corsi P \& Davidson I 2005 Polar nuclear localization of H1T2, a histone $\mathrm{H} 1$ variant, required for spermatid elongation and DNA condensation during spermiogenesis. PNAS 102 2808-2813.

McKittrick E, Gafken PR, Ahmad K \& Henikoff S 2004 Histone H3.3 is enriched in covalent modifications associated with active chromatin. PNAS 101 1525-1530.

Meistrich ML, Bucci LR, Trostle-Weige PK \& Brock WA 1985 Histone variants in rat spermatogonia and primary spermatocytes. Developmental Biology 112 230-240.
Miyamoto T, Hasuike S, Yogev L, Maduro MR, Ishikawa M, Westphal H \& Lamb DJ 2003 Azoospermia in patients heterozygous for a mutation in SYCP3. Lancet 362 1714-1719.

Mocarelli PP, Brambilla PP, Gerthoux PPM, Patterson DDG \& Needham LLL 1996 Change in sex ratio with exposure to dioxin. Lancet 348409.

Monk M, Boubelik M \& Lehnert S 1987 Temporal and regional changes in DNA methylation in the embryonic, extraembryonic and germ cell lineages during mouse embryo development. Development 99 371-382.

Morelli MA \& Cohen PE 2005 Not all germ cells are created equal: aspects of sexual dimorphism in mammalian meiosis. Reproduction 130 $761-781$.

Morgan HD, Sutherland HG, Martin DI \& Whitelaw E 1999 Epigenetic inheritance at the agouti locus in the mouse. Nature Genetics 23 314-318.

Morgan HD, Santos F, Green K, Dean W \& Reik W 2005 Epigenetic reprogramming in mammals. Human Molecular Genetics 14 R47-R58.

Nakao M 2001 Epigenetics: interaction of DNA methylation and chromatin. Gene 278 25-31.

Namekawa SH, Park PJ, Zhang LF, Shima JE, McCarrey JR, Griswold MD \& Lee JT 2006 Postmeiotic sex chromatin in the male germline of mice. Current Biology 16 660-667.

Narlikar GJ, Fan HY \& Kingston RE 2002 Cooperation between complexes that regulate chromatin structure and transcription. Cell 108 475-487.

Ng HH \& Bird A 1999 DNA methylation and chromatin modification. Current Opinion in Genetics \& Development 9 158-163.

Nimura K, Ishida C, Koriyama H, Hata K, Yamanaka S, Li E, Ura K \& Kaneda Y 2006 Dnmt3a2 targets endogenous Dnmt3L to ES cell chromatin and induces regional DNA methylation. Genes to Cells: Devoted to Molecular \& Cellular Mechanisms 11 1225-1237.

O'Bryan MK \& de Kretser D 2006 Mouse models for genes involved in impaired spermatogenesis. International Journal of Andrology 29 76-89 discussion 105-108.

O'Carroll D, Scherthan H, Peters AH, Opravil S, Haynes AR, Laible G, Rea S, Schmid M, Lebersorger A, Jerratsch $M$ et al. 2000 Isolation and characterization of Suv39h2, a second histone H3 methyltransferase gene that displays testis-specific expression. Molecular and Cell Biology 20 9423-9433.

Okada Y, Scott G, Ray MK, Mishina Y \& Zhang Y 2007 Histone demethylase JHDM2A is critical for Tnp1 and Prm1 transcription and spermatogenesis. Nature 450 119-123.

Okamoto I, Arnaud D, Le Baccon P, Otte AP, Disteche CM, Avner P \& Heard E 2005 Evidence for de novo imprinted X-chromosome inactivation independent of meiotic inactivation in mice. Nature $\mathbf{4 3 8}$ 369-373.

Ooi SK, Qiu C, Bernstein E, Li K, Jia D, Yang Z, Erdjument-Bromage H, Tempst P, Lin SP, Allis CD et al. 2007 DNMT3L connects unmethylated lysine 4 of histone $\mathrm{H} 3$ to de novo methylation of DNA. Nature $\mathbf{4 4 8}$ 714-717.

Oswald J, Engemann S, Lane N, Mayer W, Olek A, Fundele R, Dean W, Reik W \& Walter J 2000 Active demethylation of the paternal genome in the mouse zygote. Current Biology 10 475-478.

Panning B \& Jaenisch R 1996 DNA hypomethylation can activate Xist expression and silence X-linked genes. Genes and Development 10 1991-2002.

Peters AH, O'Carroll D, Scherthan H, Mechtler K, Sauer S, Schofer C, Weipoltshammer K, Pagani M, Lachner M, Kohlmaier A et al. 2001 Loss of the Suv39h histone methyltransferases impairs mammalian heterochromatin and genome stability. Cell 107 323-337.

Rakyan VK, Chong S, Champ ME, Cuthbert PC, Morgan HD, Luu KV \& Whitelaw E 2003 Transgenerational inheritance of epigenetic states at the murine Axin(Fu) allele occurs after maternal and paternal transmission. PNAS 100 2538-2543.

Redon C, Pilch D, Rogakou E, Sedelnikova O, Newrock K \& Bonner W 2002 Histone H2A variants H2AX and H2AZ. Current Opinion in Genetics \& Development 12 162-169.

Rodenhiser DD \& Mann MM 2006 Epigenetics and human disease: translating basic biology into clinical applications. Canadian Medical Association Journal $\mathbf{1 7 4} 341$.

Roeder GS 1997 Meiotic chromosomes: it takes two to tango. Genes and Development 11 2600-2621. 
Rogers RS, Inselman A, Handel MA \& Matunis MJ 2004 SUMO modified proteins localize to the $X Y$ body of pachytene spermatocytes. Chromosoma 113 233-243.

Ryan JJ, Amirova Z \& Carrier G 2002 Sex ratios of children of Russian pesticide producers exposed to dioxin. Environmental Health Perspectives 110 A699-A701.

La Salle S, Oakes CC, Neaga OR, Bourc'his D, Bestor TH \& Trasler JM 2007 Loss of spermatogonia and wide-spread DNA methylation defects in newborn male mice deficient in DNMT3L. BMC Developmental Biology 7104.

Schotta G, Lachner M, Sarma K, Ebert A, Sengupta R, Reuter G, Reinberg D \& Jenuwein T 2004 A silencing pathway to induce H3-K9 and H4-K20 trimethylation at constitutive heterochromatin. Genes and Development 18 1251-1262.

Shiio Y \& Eisenman RN 2003 Histone sumoylation is associated with transcriptional repression. PNAS 100 13225-13230.

Skuse DH 2005 X-linked genes and mental functioning. Human Molecular Genetics 14 R27-R32.

Sonnack V, Failing K, Bergmann M \& Steger K 2002 Expression of hyperacetylated histone $\mathrm{H} 4$ during normal and impaired human spermatogenesis. Andrologia 34 384-390.

Stopka T \& Skoultchi A 2003 The ISWI ATPase Snf2h is required for early mouse development. PNAS 100 14097-14102.

Suetake I, Shinozaki F, Miyagawa J, Takeshima H \& Tajima S 2004 DNMT3L stimulates the DNA methylation activity of Dnmt3a and Dnmt3b through a direct interaction. Journal of Biological Chemistry $27927816-27823$.

Suetake I, Morimoto Y, Fuchikami T, Abe K \& Tajima S 2006 Stimulation effect of Dnmt3L on the DNA methylation activity of Dnmt3a2. Journal of Biochemistry 140 553-559.

Tachibana M, Nozaki M, Takeda N \& Shinkai Y 2007 Functional dynamics of $\mathrm{H} 3 \mathrm{~K} 9$ methylation during meiotic prophase progression. EMBO Journal 26 3346-3359.

Takada Y, Isono K, Shinga J, Turner JM, Kitamura H, Ohara O, Watanabe G, Singh PB, Kamijo T, Jenuwein T et al. 2007 Mammalian Polycomb Scmh1 mediates exclusion of Polycomb complexes from the XY body in the pachytene spermatocytes. Development 134 579-590.

Tanaka H \& Baba T 2005 Gene expression in spermiogenesis. Cellular and Molecular Life Sciences 62 344-354.

Tarsounas M \& Moens PB 2001 Checkpoint and DNA-repair proteins are associated with the cores of mammalian meiotic chromosomes. Current Topics in Developmental Biology 51 109-134.

Turner JM 2007 Meiotic sex chromosome inactivation. Development 134 1823-1831.

Turner JM, Aprelikova O, Xu X, Wang R, Kim S, Chandramouli GV, Barrett JC, Burgoyne PS \& Deng CX 2004 BRCA1, histone H2AX phosphorylation, and male meiotic sex chromosome inactivation. Current Biology 14 2135-2142.

Turusov VS, Nikonova TV \& Parfenov Yu D 1990 Increased multiplicity of lung adenomas in five generations of mice treated with benz(a)pyrene when pregnant. Cancer Letters 55 227-231.

Walsh CP \& Bestor TH 1999 Cytosine methylation and mammalian development. Genes and Development 13 26-34.
Wang HB \& Zhang Y 2001 Mi2, an auto-antigen for dermatomyositis, is an ATP-dependent nucleosome remodeling factor. Nucleic Acids Research 29 2517-2521.

Webster KE, O'Bryan MK, Fletcher S, Crewther PE, Aapola U, Craig J, Harrison DK, Aung H, Phutikanit N, Lyle R et al. 2005 Meiotic and epigenetic defects in Dnmt3L-knockout mouse spermatogenesis. PNAS 102 4068-4073.

Wouters-Tyrou D, Martinage A, Chevaillier P \& Sautiere P 1998 Nuclear basic proteins in spermiogenesis. Biochimie 80 117-128.

Wu JY, Ribar TJ, Cummings DE, Burton KA, McKnight GS \& Means AR 2000 Spermiogenesis and exchange of basic nuclear proteins are impaired in male germ cells lacking Camk4. Nature Genetics 25 448-452.

Yan W, Ma L, Burns KH \& Matzuk MM 2003 HILS1 is a spermatid-specific linker histone $\mathrm{H} 1$-like protein implicated in chromatin remodeling during mammalian spermiogenesis. PNAS 100 10546-10551.

de Yebra L, Ballesca JL, Vanrell JA, Bassas L \& Oliva R 1993 Complete selective absence of protamine P2 in humans. Journal of Biological Chemistry 268 10553-10557.

Yu YE, Zhang Y, Unni E, Shirley CR, Deng JM, Russell LD, Weil MM, Behringer RR \& Meistrich ML 2000 Abnormal spermatogenesis and reduced fertility in transition nuclear protein 1-deficient mice. PNAS 97 4683-4688.

Zambrano E, Martinez-Samayoa PM, Bautista CJ, Deas M, Guillen L, Rodriguez-Gonzalez GL, Guzman C, Larrea F \& Nathanielsz PW 2005 Sex differences in transgenerational alterations of growth and metabolism in progeny (F2) of female offspring (F1) of rats fed a low protein diet during pregnancy and lactation. Journal of Physiology 566 225-236.

Zhang Y \& Reinberg D 2001 Transcription regulation by histone methylation: interplay between different covalent modifications of the core histone tails. Genes and Development 15 2343-2360.

Zhao M, Shirley CR, Yu YE, Mohapatra B, Zhang Y, Unni E, Deng JM, Arango NA, Terry NH, Weil MM et al. 2001 Targeted disruption of the transition protein 2 gene affects sperm chromatin structure and reduces fertility in mice. Molecular and Cell Biology 21 7243-7255.

Zhao M, Shirley CR, Hayashi S, Marcon L, Mohapatra B, Suganuma R, Behringer RR, Boissonneault G, Yanagimachi R \& Meistrich ML 2004 Transition nuclear proteins are required for normal chromatin condensation and functional sperm development. Genesis 38 200-213.

Zhu B, Zheng Y, Pham AD, Mandal SS, Erdjument-Bromage H, Tempst P \& Reinberg D 2005 Monoubiquitination of human histone $\mathrm{H} 2 \mathrm{~B}$ : the factors involved and their roles in HOX gene regulation. Molecular Cell 20 601-611.

Zorn B, Sucur V, Stare J \& Meden-Vrtovec H 2002 Decline in sex ratio at birth after 10-day war in Slovenia: brief communication. Human Reproduction 17 3173-3177.

Received 23 December 2007

First decision 15 February 2008

Revised manuscript received 1 April 2008

Accepted 14 May 2008 